\title{
A Bayesian Examination of Information and Uncertainty in
}

\section{Contingent Valuation}

\author{
David M. Aadland, Arthur J. Caplan and Owen R. Phillips*
}

July 2007

\footnotetext{
*Aadland and Phillips are respectively associate and full professors at the Department of Economics and Finance, University of Wyoming, PO Box 3985, Laramie, WY, 82071-3985, USA; 307-766-4931 (Aadland phone); 307-766-5090 (fax); aadland@uwyo.edu (e-mail). Caplan is an associate professor at the Department of Economics, Utah State University, 3530 Old Main Hill, Logan, UT 84341. Support from the Paul Lowham Research Fund is gratefully appreciated. We thank Chris McIntosh and Neil Wilmot for their assistance with the experiments. Helpful comments on earlier drafts were received from participants at the American Agricultural Economic Association meetings, Western Agricultural Economic Association annual meetings, the joint U.S. Forest Service / Colorado State University seminar series and the CU Environmental and Resource Economics Workshop.
} 


\title{
A Bayesian Examination of Information and Uncertainty in Contingent Valuation
}

\begin{abstract}
A theoretical framework is presented to explain how agents respond to information under uncertainty in contingent valuation surveys. Agents are provided with information signals and referendum prices as part of the elicitation process. Agents use Bayesian updating to revise prior distributions. An information prompt is presented to reduce hypothetical bias. However, we show the interaction between anchoring and the information prompt creates a systematic bias in willingness to pay. We test our hypotheses in an experimental setting where agents are asked to make a hypothetical, voluntary contribution to a public good. Experimental results are consistent with the model.
\end{abstract}

JEL Codes: Q51, C11, C91

Keywords: Bayesian Updating, Anchoring, Signals, Contingent Valuation 
A person's willingness to pay (WTP) for a good or service is often unknown before the consumer participates in a market or contributes to the provision of a public good. Frequently, potential consumers are surveyed about their WTP before making payment or even before the good exists. These surveys are conducted using written, oral or visual descriptions, often quite vague, of goods not yet fully developed. Under such circumstances, WTP is elicited in an environment of uncertainty causing agents to search for signals during the survey process that will help them arrive at an improved WTP estimate. Our goal in this paper is to provide a theoretical foundation that describes how agents react to various types of information about the good during the value elicitation process. It is natural to treat this reaction process as a Bayesian-updating problem, since agents are being provided with new information for which they can revise their WTP. ${ }^{1}$

Our focus is on the contingent valuation (CV) survey method, which uses hypothetical responses to estimate consumers' WTP. ${ }^{2}$ A central problem with surveys like the CV method of elicitation is that agents are not in real market environments; stated values are prone to hypothetical bias. ${ }^{3}$ Agents often knowingly or unknowingly misrepresent their true preferences for the good in a hypothetical settings. True preferences are revealed in actual markets or when it comes time to contribute to the provision of a public good. In response, researchers have proposed remedies such as combining revealed and stated preference data (Adamowicz, Louviere and Williams (1994)), calibrating hypothetical responses to actual choices (Johannesson, Blomquist, Blumenschein, Johansson, Liljas and O'Conor (1999)), and providing explicit information prompts or signals prior to the WTP questions with the hope that respondents will self correct with the new information.

\footnotetext{
${ }^{1}$ Bayesian updating has been used to describe decision making under uncertainty in a variety of economic contexts such as learning about workplace risk (Viscusi and O'Connor (1984)), herding behavior and information cascades (Anderson and Holt (1997)), and global climate change (Cameron (2005)).

${ }^{2}$ This method has been a popular method for eliciting the value of non-market goods. For an overview of this literature see Brookshire, Thayer, Schulze and D'Arge (1982), Hausman (1993), Mitchell and Carson (1989), and Cummings, Brookshire and Schulze (1986).

${ }^{3}$ See Murphy, Allen, Stevens and Weatherhead (forthcoming) for a review of the hypothetical bias literature in contingent valuation.
} 
The information is not limited to, but might inform agents about budget constraints, substitute goods, or the extent to which preferences have been misrepresented in previous surveys.

Much of this information is referred to as "cheap talk" (Cummings and Taylor (1999)), a term with origins in the game theory literature. Gibbons (1992, p.210) refers to cheap talk as "costless, nonbinding, nonverifiable claims." They are signals that have no credibility. In survey contexts, agents may treat cheap talk as completely non-informative and ignore it, while in other contexts it may be considered partially informative. Our theory treats cheap talk in CV studies as a partially informative signal sent to respondents - one that agents will act on and use to update the uncertain value they place on the good. Henceforth, we will refer to the information given prior to the elicitation of WTP in CV surveys as cheap talk.

We apply our theory to a referendum CV study where agents are first given cheap talk and then provided a single referendum price. ${ }^{4}$ Agents are prone to have a bias while formulating their WTP. The bias is modeled as a stochastic component of utility (and thus WTP) over which agents form priors. Priors are updated in a Bayesian manner as agents are provided with cheap talk and an opening price for the non-market, public good. ${ }^{5}$ The agent then forms a rational, updated estimate of the distribution of his or her stochastic bias term and uses this estimate to calibrate a WTP response. By modeling the agent's problem this way, we make transparent the process by which signals are used to resolve uncertainty regarding the value of the good.

In our model, agents rationally anchor their WTP estimates to an announced price in a manner that depends on whether or not they received cheap talk. This dependence is important because the effectiveness of cheap talk in reducing hypothetical bias is usually tested by comparing the

\footnotetext{
${ }^{4}$ We later extend our theory to address the double-bounded dichotomous choice (DBDC) format, where the issue of incentive incompatibility is discussed.

${ }^{5}$ Herriges and Shogren (1996) and McLeod and Bergland (1999) use a Bayesian approach to examine the issues of anchoring bias (where agents are induced by the question format itself to anchor their responses to an opening referendum price) and incentive incompatibility (where agents are induced by the question format to provide untruthful responses) in CV surveys. Unlike their studies, however, we aim to provide a more formal and general theory of the origins of hypothetical bias and the Bayesian updating process during the value elicitation process.
} 
actions of those receiving cheap talk (the treatment group) with those who do not (the control group). Consequently, differences between the treatment and control groups that are attributed solely to cheap talk may instead reflect differences in how agents anchor their WTP estimates to announced prices. And unlike other studies that have estimated anchoring effects in CV (Chanel, Aprahamian and Luchini (forthcoming); Whitehead (2002)), our specification allows us to econometrically identify the anchoring effect without need for a follow-up price.

We propose an experimental design for a hypothetical public good and run a series of treatments that separate the effect of cheap talk from anchoring. Our experimental design distinguishes the effects of anchoring and cheap talk in the valuation of a generic public good by mimicking the way $\mathrm{CV}$ surveys are typically implemented in practice, that is, subjects receive different price announcements presented as take-it-or-leave-it choices. By dividing our sample into two treatments involving a hypothetical contribution toward a public good - one without cheap talk and one with cheap talk - we are able to measure the extent to which anchoring and cheap talk interact in the context of a Bayesian updating process.

Our principal finding is that the interaction between anchoring and cheap talk manifests itself as an upward bias in the observed cheap talk effect when the announced price is relatively high, and as a downward bias when the announced prices is relatively low. This result is consistent with several recent empirical papers on the subject and provides one explanation for the conflicting empirical results associated with hypothetical bias and cheap talk in the CV literature. ${ }^{6}$

\footnotetext{
${ }^{6}$ The empirical evidence is mixed on whether cheap talk is, in general, an effective means of eliminating hypothetical bias in CV and field experiments. Cummings and Taylor (1999) find that a long cheap-talk script is effective in eliminating hypothetical bias. List (2001) and Lusk (2003) use a script similar to that of Cummings and Taylor and find that cheap talk only works for inexperienced consumers. Poe, Clark, Rondeau and Schulze (2002) report that a shorter cheap-talk script is ineffective in eliminating hypothetical bias; Loomis, Gonzalez-Caban and Gregory (1994) and Neil (1995) find that reminders about budget constraints and substitutes also are ineffective. Aadland and Caplan (2003) find that, although cheap talk is ineffective overall, it successfully reduces hypothetical bias for certain groups of respondents. However in other work, Cummings, Harrison and Taylor (1995) and Aadland and Caplan (2006) use a shorter script and find that cheap talk may even exacerbate the hypothetical bias. We offer a theory that is independent of script length and has the potential to explain some of the results that script length cannot. We note, however, that it would be fairly straightforward to incorporate a script-length effect into our
} 


\section{Theoretical Framework}

Assume a continuum of agents indexed on the unit interval. Representative agent $i \in(0,1)$ maximizes utility

$$
u_{i}=u\left(z_{i}, G\left(\eta_{i}\right) ; \theta_{i}\right)
$$

by choosing a vector of private goods, $z_{i}$. Each agent's valuation of the public good, $G$, depends on a stochastic component $\eta_{i}$ (discussed below). $\theta_{i}$ is a vector of individual-specific characteristics excluding income level. The agent's budget constraint is

$$
m_{i} \geq p^{\prime} z_{i}+g_{i}
$$

where $m_{i}$ is income, $p$ is a vector of prices corresponding to $z$, and $g_{i} \geq 0$ is an exogenously determined lump-sum payment toward the provision of $G$. We assume that the sum of the total private contributions, $\int_{i} g_{i} d i$, results in provision of the public good at level $G$.

We invoke the standard assumption that utility is strictly increasing and quasi-concave in both the private and public goods. The term $\eta_{i}$ reflects the notion that agents are not always capable of accurately assessing the value of the public good due to a lack of experience with the good or potential bias in a hypothetical setting. In particular, agents with $\eta_{i}>0$ tend to overestimate their WTP for $G$, agents with $\eta_{i}<0$ tend to underestimate their WTP for $G$, while agents with $\eta_{i}=0$ accurately assess their WTP for $G$. As we show below, although agents attempt to correct for the bias via their interactions with the interviewer in a hypothetical assessment, they do not necessarily have adequate information to completely eliminate it.

As is common in the literature, we refer to hypothetical bias as the tendency to misstate true WTP when in a hypothetical rather than a real market environment. This definition is sufficiently

Bayesian framework whereby long scripts evoke a larger WTP revision than short scripts. 
broad to accommodate many of the different biases associated with nonmarket valuation, such as strategic bias, awareness bias, nay-saying, yeah-saying, etc. In particular, our theory assumes that hypothetical bias is stochastic and involves a respondent continually updating and estimating the degree of personal bias using a Bayesian approach. In our view, this is the most natural way to think about hypothetical bias but note that it could instead result deterministically, e.g., as a "purchase of moral satisfaction" (Kahneman and Knetsch (1992)) or as a desire to conform socially (Bernheim (1994)). In these cases, one might think of cheap talk as an updating mechanism that instills guilt in the respondent (for knowingly reporting an untruthful WTP) rather than a mechanism that reduces uncertainty.

Let $z_{i}^{*}=z\left(p, m_{i}-g_{i}, G\left(\eta_{i}\right) ; \theta_{i}\right)$ represent the agent's optimal choice of the private good vector, implying indirect utility level $u_{i}^{*}=u\left(z_{i}^{*}, G\left(\eta_{i}\right) ; \theta_{i}\right)$. The corresponding minimum expenditure function, defined with respect to net income, $m_{i}-g_{i}$, is

$$
e_{i}=e\left(p, G\left(\eta_{i}\right), u_{i}^{*} ; \theta_{i}\right)=m_{i}-g_{i}
$$

Using (3), the agent's WTP for $G$ is derived as

$$
W T P_{i}=e\left(p, G=0, u_{i}^{*} ; \theta_{i}\right)-e\left(p, G\left(\eta_{i}\right), u_{i}^{*} ; \theta_{i}\right)
$$

which is the difference between the minimum expenditure required to achieve utility level $u_{i}^{*}$ without and with the public good. Due to the presence of $\eta_{i}$, (4) reflects the agent's perceived, rather than true, WTP for the public good. Accordingly, we characterize perceived $W T P_{i}$ as:

$$
W T P_{i}=W T P_{i}\left(\eta_{i}=0\right)+\delta_{i},
$$


where $W T P_{i}\left(\eta_{i}=0\right)$ is "true" WTP and $\delta_{i}$ is a random variable with density function $p\left(\delta_{i}\right)$ and population mean

$$
\mu=\int \delta_{i} p\left(\delta_{i}\right) d \delta_{i}
$$

We assume that $\delta_{i}$ reflects the agent's innate tendency to incorrectly estimate WTP for the public good. While agents do not know $p\left(\delta_{i}\right)$, they do hold prior beliefs regarding the distribution for $\delta_{i}$. Based on this subjective probability distribution for $\delta_{i}$, they form a corresponding expectation denoted by $E_{i}\left(\delta_{i}\right)$. This expectation represents the agent's initial evaluation of personal bias. For example, if $\delta_{i}>E_{i}\left(\delta_{i}\right)=0$, then the agent does not recognize that he is overvaluing the public good and thus a positive bias exists. Another possibility is that $\delta_{i}>E_{i}\left(\delta_{i}\right)>0$, in which case the agent suspects that he is overvaluing the public good, but only partially corrects for the bias.

We refer to the agent's initial perceived WTP as $W T P_{i}^{0}$, which is given by (5). However, as the agent receives information (assumed from the interviewer), the agent revises $W T P_{i}$ in an attempt to reduce the influence of $\delta_{i}$ and bring perceived WTP closer to the true WTP. The agent thus forms

$$
W T P_{i}^{1}=E_{i}\left(W T P_{i} \mid s_{i}\right)=W T P_{i}^{0}-E_{i}\left(\delta_{i} \mid s_{i}\right)
$$

where $E_{i}\left(W T P_{i} \mid s_{i}\right)$ is agent $i$ 's expectation of $W T P_{i}$ conditional upon the information contained in the signal vector $s_{i}$. From (5) and (7), we see that clear signals provided by the interviewer regarding the population mean of $\delta_{i}$ are, on average, likely to bring perceived WTP closer to the true WTP.

\section{$1.1 \quad$ Bayesian Updating}

Each agent faces a Bayesian-updating problem with a subjective prior distribution for $\delta_{i}, h_{i}\left(\delta_{i}\right)$. Henceforth, we assume $E_{i}\left(\delta_{i}\right)=0$ so that the agent initially perceives no bias in valuing the public 
good. After receiving the signal $s_{i}$ from the interviewer, the agent then uses Bayes' formula to form the posterior distribution for $\delta_{i}$ :

$$
k_{i}\left(\delta_{i} \mid s_{i}\right) \propto g_{i}\left(s_{i} \mid \delta_{i}\right) h_{i}\left(\delta_{i}\right)
$$

where $g_{i}\left(s_{i} \mid \delta_{i}\right)$ is the distribution for $s_{i}$ conditional on $\delta_{i}$. The function $g_{i}\left(s_{i} \mid \delta_{i}\right)$ captures the essence of the revisions to beliefs about $\delta_{i}$ by directly accounting for the interaction between $\delta_{i}$ and $s_{i}$. Assuming a quadratic loss function, the agent then responds "rationally" to $s_{i}$ by forming an updated expectation of $\delta_{i}$ using $^{7}$

$$
E_{i}\left(\delta_{i} \mid s_{i}\right)=\int \delta_{i} k_{i}\left(\delta_{i} \mid s_{i}\right) d \delta_{i}
$$

\section{Application to a Referendum CV Survey}

To elicit $W T P_{i}$ for a public good in a referendum CV format, the interviewer presents the agent with a hypothetical price for the public good, $\tau_{i} \cdot{ }^{8} \quad$ The agent then compares $W T P_{i}^{1}$ to $\tau_{i}$, and hypothetically buys into the public good if $W T P_{i}^{1}>\tau_{i}$ and declines otherwise. The point of reference is $W T P_{i}^{1}$ because prior to offering the price $\tau_{i}$, the interviewer presents the agent with a signal, represented as a draw $c_{i} \in\{0, \mu\}$. A draw of $c_{i}=0$ represents no additional information, while a draw of $c_{i}=\mu>0$ informs the agent of $\delta_{i}$ 's population mean. ${ }^{9}$

\footnotetext{
${ }^{7}$ See Hogg and Craig (1978) for a discussion of Bayesian estimation.

${ }^{8}$ Throughout the paper, we refer to $\tau_{i}$ as the "announced price". In the contingent valuation literature, it is common to refer to $\tau_{i}$ as the "referendum bid" or "bid". We avoid using the term bid in this paper so as not to create any confusion associated with its use in other areas of economics such as auction theory. In the experiment described below subjects are presented with "investment" levels in the public good.

${ }^{9}$ In practice, not all cheap-talk scripts directly inform agents of the magnitude of the hypothetical bias. Instead they often report differences in actual and hypothetical participation rates for public programs or goods (e.g., Cummings and Taylor (1999); Lusk (2003)), percentage difference in stated and revealed WTP (e.g., List (2001)), or make a general statement that WTP tends to be misstated in hypothetical scenarios (e.g., Carlsson, Frykblom and Lagerkvist (2005) and Aadland and Caplan (2006)). It would be fairly straightforward to modify our theory so that, rather than being directly informed of $\mu$ and knowing it with certainty, the agent received an indirect signal about $\mu$ and was required to infer its value.
} 
Based on $c_{i}$, we therefore have two scenarios to consider.

\subsection{No Hypothetical-Bias Signal}

We begin by considering the case where the agent receives the signal $s_{i}^{0}=\left\{c_{i}=0, \tau_{i}\right\}$. Because no signal is sent prior to the price $\tau_{i}$, revisions to $\delta_{i}$ are exclusively due to information contained in $\tau_{i}$. For this scenario, we assume

$$
E_{i}\left(\delta_{i} \mid s_{i}^{0}\right)=\alpha\left(W T P_{i}^{0}-\tau_{i}\right)
$$

where $0<\alpha<1$. Equation (10) states that in revising the bias estimate, the agent considers the bias to be a fraction of the difference between the initial WTP estimate and the announced price. Implicit in (10) is the fact that the agent perceives $\tau_{i}$ as a signal that the interviewer has private information regarding the true WTP distribution. Substituting (10) into (7), we obtain an updated WTP $\left(W T P_{i}^{1}\right)$ via the function

$$
W T P_{i}^{1}=(1-\alpha) W T P_{i}^{0}+\alpha \tau_{i}
$$

This updating function is equivalent to the one presented in Herriges and Shogren (1996). ${ }^{10}$

There is strong evidence to support the notion of anchoring, beginning with the seminal work of Kahneman and Tversky. ${ }^{11}$ Tversky and Kahneman (1974) describe anchoring as a heuristic where "people make estimates by starting from an initial value that is adjusted to yield the final answer." They famously illustrate the anchoring phenomenon by asking subjects to estimate

\footnotetext{
${ }^{10}$ The weighted-average form of the updating function in (11) results if $g_{i}\left(s_{i} \mid \delta_{i}\right)$ is a normal distribution and $\alpha=\sigma_{h}^{2} /\left(\sigma_{g}^{2}+\sigma_{h}^{2}\right)$, where $\sigma_{g}^{2}$ is the variance of $g_{i}\left(s_{i} \mid \delta_{i}\right)$ and $\sigma_{h}^{2}$ is the variance of the prior distribution $h_{i}\left(\delta_{i}\right)$. The formal derivation of (11) is shown in Appendix A.

${ }^{11}$ See Laibson and Zeckhauser (1998) for a discussion that relates Kahneman and Tversky's work to the burgeoning field of "behavioral economics".
} 
various quantities (stated in percentages), such as the number of African countries in the United Nations. The final percentage estimates were inexplicably correlated to the arbitrary numbers provided by the spinning of a wheel of fortune. Anchoring has been reported in a myriad of other contexts: Armantier (2006) across consecutive surveys relating to subjective estimates of lethal risks; Hurd (1999) in surveys that use brackets to elicit household assets; and McFadden (2001) in CV referendum surveys. McFadden (2001, p. 364) explains the presence of anchoring by stating that...

A psychological explanation for anchoring is that a prompt creates in the subject's mind, at least temporarily, the possibility that the uncertain quantity could be either above or below the prompt...Education trains individuals to use problem-solving protocols in which responses to questions are based not only on substantive knowledge, but also on contextual cues as to what a correct response might be. Consequently, it is no surprise if subjects apply these protocols and use numerical prompts in forming responses.

To clarify the effects of anchoring in our context, consider the following. Suppose the agent begins with an initial perceived valuation of the public good, $W T P_{i}^{0}$, which is based on a noninformative prior and initial expectation of bias $E_{i}\left(\delta_{i}\right)=0$. The agent is then confronted with an announced price such that $\tau_{i}>W T P_{i}^{0}$. This price anchors perceptions. The agent interprets this information as indicating that the true WTP value is likely to be somewhere between $W T P_{i}^{0}$ and $\tau_{i}$. As a result, the agent now places a larger probability on outcomes where $\delta_{i}<0$ and infers that the perceived distribution for $\delta_{i}$ needs to be shifted to the left. This implies that the agent revises the perceived WTP upward toward $\tau_{i}$, resulting in $W T P_{i}^{1}>W T P_{i}^{0}$. Conversely, when $\tau_{i}<W T P_{i}^{0}$, the agent assumes it is now more probable that $\delta_{i}>0$ and that the initial WTP was biased upward. In this case, the agent revises the perceived WTP downward toward $\tau_{i}$, resulting 
in $W T P_{i}^{1}<W T P_{i}^{0}$. Finally, when $s_{i}^{0}$ does not reveal any new information (i.e., when $c_{i}=0$ and $\left.\tau_{i}=W T P_{i}^{0}\right)$, the agent does not revise the initial expectations and sets $W T P_{i}^{1}=W T P_{i}^{0}$.

\subsection{A Signal About The Mean of Hypothetical Bias}

Next, consider the case where the agent receives the sequential signal $s_{i}^{1}=\left\{c_{i}=\mu, \tau_{i}\right\}$. In other words, prior to receiving the announced price the agent receives the signal that $\delta_{i}$ has population mean $\mu$. This does not imply that the agent now knows $\delta_{i}$ with certainty, only that it is drawn from a distribution with mean $\mu$.

We assume that in response to the initial signal $c_{i}=\mu$, the agent revises the estimate of $\delta_{i}$ so that $E_{i}\left(\delta_{i} \mid c_{i}=\mu\right)=\mu .^{12}$ The agent therefore estimates that his or her individual bias is equal to the average bias in the population. Next, the agent compares the adjusted WTP $\left(W T P_{i}^{0}-\mu\right)$ to $\tau_{i}$ and uses a variation of equation (10) to update the estimate of $\delta_{i}$ :

$$
E_{i}\left(\delta_{i} \mid s_{i}^{1}\right)=\mu+\gamma\left(W T P_{i}^{0}-\mu-\tau_{i}\right)
$$

where $0<\gamma<1$. This implies

$$
W T P_{i}^{1}=(1-\gamma)\left(W T P_{i}^{0}-\mu\right)+\gamma \tau_{i}
$$

To test whether the cheap-talk signal $c_{i}=\mu$ is effective in eliminating hypothetical bias, the

\footnotetext{
${ }^{12}$ Some may argue that agents are unlikely to adjust their WTP perfectly to the signal $c_{i}=\mu$. For simplicity, we assume perfect adjustments; however it is important to recognize that the subsequent results are robust to partial adjustments where $0<E_{i}\left(\delta_{i} \mid c_{i}=\mu\right)<\mu$.
} 
relevant measure is

$$
\begin{aligned}
\Delta_{i} & \equiv E_{i}\left(W T P_{i} \mid s_{i}^{1}, W T P_{i}^{0}\right)-E_{i}\left(W T P_{i} \mid s_{i}^{0}, W T P_{i}^{0}\right) \\
& =(\alpha-\gamma)\left(W T P_{i}^{0}-\tau_{i}\right)+(\gamma-1) \mu .
\end{aligned}
$$

If, for example, $\Delta_{i}=-\mu$, we would conclude that cheap talk successfully reduced agent $i$ 's WTP bias by $\mu$. We now discuss several different cases that depend on the relative values of $\alpha, \gamma, W T P_{i}^{0}$, and $\tau_{i}$.

\subsubsection{Case 1. Common Anchoring Structure $(\gamma=\alpha)$}

We begin with the case where $\gamma=\alpha$, that is, the agent anchors to $\tau_{i}$ in the same fashion with or without cheap talk. Equation (13) then collapses to $\Delta_{i}=(\gamma-1) \mu$, which implies that even when cheap talk reduces initial WTP by exactly $\mu$, anchoring makes it appear that cheap talk was only partially effective (i.e., $\Delta_{i}>-\mu$ ). Furthermore, as $\alpha=\gamma \rightarrow 1$, cheap talk appears to have no effect because the anchoring completely overshadows the cheap-talk adjustment.

Figure 1 depicts the interaction between cheap talk and anchoring bias for Case 1, assuming $W T P_{i}^{0}-\mu>\tau_{i}$. Panel A shows the prior and posterior distributions for $\delta_{i}$ when the agent receives the signal $s_{i}^{1}$. The agent begins with the prior distribution $h_{i}\left(\delta_{i}\right)$. After receiving the signal $c_{i}=\mu$, the agent then revises the distribution to $k_{i}\left(\delta_{i} \mid c_{i}=\mu\right)$, leading to a revised WTP equal to $W T P_{i}^{0}-\mu$. Next, the agent receives the price $\tau_{i}$ and further revises the distribution to $k_{i}\left(\delta_{i} \mid c_{i}=\mu, \tau_{i}\right)$ or $k_{i}\left(\delta_{i} \mid s_{i}^{1}\right)$ with conditional mean $W T P_{i}^{1}$. In Panel B, the agent begins with the same prior, receives price $\tau_{i}$ without having been subjected to any cheap talk, and then revises the distribution for $\delta_{i}$ to $k_{i}\left(\delta_{i} \mid c_{i}=0, \tau_{i}\right)$ or $k_{i}\left(\delta_{i} \mid s_{i}^{0}\right)$. In comparing Panels $\mathrm{A}$ and $\mathrm{B}$, note that although $W T P_{i}^{1}$ is farther to the left in Panel A than in Panel B, the difference between the two is less than 
$\mu$. As a result, when testing for cheap talk, we incorrectly conclude that cheap talk only partially eliminates the bias $\mu$.

To clarify, consider the following numerical example. Suppose the agent's $W T P_{i}^{0}=\$ 10$ and the cheap-talk signal is $c_{i}=\mu=\$ 4$. The agent then adjusts initial WTP to be consistent with the first signal (i.e., $W T P_{i}^{0}-\mu=\$ 6$ ) and compares this to the announced price, which we assume is $\tau_{i}=\$ 2$. Letting $\alpha=\gamma=0.5, W T P_{i}^{1}=(0.5 \times 6)+(0.5 \times 2)=\$ 4$ with an anchoring effect of $\$ 4-\$ 6=-\$ 2 . \quad$ By comparison, when $c_{i}=0$ the agent sets $W T P_{i}^{1}=(0.5 \times 10)+(0.5 \times 2)=\$ 6$, implying an anchoring effect of $\$ 6-\$ 10=-\$ 4$. Note that although cheap talk reduces initial WTP exactly as anticipated, because of the interaction with anchoring bias, cheap talk appears to be only partially effective (i.e., $\Delta_{i}=\$ 4-\$ 6=-\$ 2>-\mu=-\$ 4$ ).

\subsubsection{Case 2. Dual Anchoring Structures $(\gamma \neq \alpha)$}

We now consider the case where the anchoring parameter is different with and without the cheaptalk signal. We assume throughout that $\gamma<\alpha$ so that the anchoring effect associated with $\tau_{i}$ is weakened by the presence of a cheap-talk signal. It is important to recognize that by assuming $\gamma<\alpha$, we are not claiming that the total effect of cheap talk and anchoring on WTP is necessarily smaller than without cheap talk, only that the marginal contribution of anchoring is weakened by the presence of cheap talk.

Begin by defining a critical announced price

$$
\tau_{i}^{*}=W T P_{i}^{0}+[\gamma /(\alpha-\gamma)] \mu
$$

which equates the measured cheap-talk effect in (13) to $-\mu$. As a result, for cheap talk to appear fully effective, the announced price must equal $W T P_{i}^{0}$ plus a positive constant $(\mu \gamma /(\alpha-\gamma))$. Figure 2 depicts the combination of $W T P_{i}^{0}$ and $\tau_{i}$ values that will result in a measured cheap-talk effect 
equal to $-\mu$. Using this $\tau_{i}^{*}$ locus and the 45 degree line from Figure 2, we define three distinct regions and discuss how they relate to $\Delta_{i}$.

Region 1. Ineffective Cheap Talk $\left(\tau_{i}<W T P_{i}^{0}\right)$. In this case, the agent receives a relatively low announced price $\tau_{i}$, corresponding to the region below the 45 degree line in Figure 2. When $c_{i}=0$, the agent then anchors downward toward $\tau_{i}$. If instead the agent receives the cheap-talk signal $c_{i}=\mu$ prior to receiving the price, then depending upon the size of $\mu$, the agent may either anchor downward toward the price (when $W T P_{i}^{0}-\mu>\tau_{i}$ ), anchor upward toward the price (when $W T P_{i}^{0}-\mu<\tau_{i}$ ) or not anchor at all (when $W T P_{i}^{0}-\mu=\tau_{i}$ ). Because $\tau_{i}<\tau_{i}^{*}$, the measured cheap-talk effect will be larger than $-\mu$. In fact, we know from (13) that $\Delta_{i}$ will be larger than $(\gamma-1) \mu$. Therefore, we are likely to mistakenly conclude that cheap talk is ineffective in eliminating the hypothetical bias, or worse yet, that it exacerbates the bias.

Region 2. Partially or Fully Effective Cheap Talk $\left(\tau_{i}^{*} \geq \tau_{i} \geq W T P_{i}^{0}\right)$. In this case, the agent receives a price that is no less than initial WTP but no greater than the critical announced price. This corresponds to the region in Figure 2 between (and including) the 45 degree line and the $\tau_{i}^{*}$ locus. First, if $\tau_{i}=W T P_{i}^{0}$, anchoring only occurs for those who receive the signal $s_{i}=\mu$. As in Case 1, (13) simplifies to $\Delta_{i}=(\gamma-1) \mu$, implying that cheap talk appears to be only partially effective. On the other hand, if $\tau_{i}=\tau_{i}^{*}$, then by (14), the measured cheap-talk effect equals $-\mu$, and cheap talk appears to be fully effective. In sum, any announced price between $\tau_{i}^{*}$ and $W T P_{i}^{0}$ leads to a measured cheap-talk effect between $(\gamma-1) \mu$ and $-\mu$.

Consider another numerical example. Suppose that $W T P_{i}^{0}=\$ 10, c_{i}=\mu=\$ 4, \alpha=0.5$ and $\gamma=0.25$, implying a critical announced price from (14) of $\tau_{i}^{*}=14$. The agent first adjusts the initial WTP to be consistent with the cheap-talk signal (i.e., $W T P_{i}^{0}-\mu=\$ 6$ ) and then compares this to an assumed price of $\tau_{i}=\$ 12$. Revised WTP is thus $W T P_{i}^{1}=(0.75 \times 6)+(0.25 \times 12)=$ 
$\$ 7.5$ with an anchoring effect of $\$ 7.5-\$ 6=\$ 1.5$. By comparison, when $c_{i}=0$ the agent sets $W T P_{i}^{1}=(0.5 \times 10)+(0.5 \times 12)=\$ 11$, implying an anchoring effect of $\$ 11-\$ 10=\$ 1$. As in Case 1, cheap talk reduces initial WTP exactly as anticipated but it appears to be only partially effective (i.e., $\Delta_{i}=\$ 7.5-\$ 11=-\$ 3.5>-\mu=-\$ 4$ ).

Region 3. Overly Effective Cheap Talk $\left(\tau_{i}>\tau_{i}^{*}\right)$. In this case, the agent receives a relatively high announced price $\tau_{i}$, corresponding to the area above the $\tau_{i}^{*}$ locus in Figure 2. After receiving the signal $s_{i}^{0}$, the agent anchors upward toward $\tau_{i}$. If the agent instead receives the signal $c_{i}=\mu$ prior to receiving the price, the agent similarly anchors upward toward the price (note that $W T P_{i}^{0}<\tau_{i}$ implies that $W T P_{i}^{0}-\mu<\tau_{i}$ as well). Because $\tau_{i}>\tau_{i}^{*}$, we know that $\Delta_{i}$ will be smaller (more negative) than $-\mu$. We therefore conclude that although cheap talk corrects for hypothetical bias, it does so by too much. ${ }^{13}$

Returning to our numerical example, we consider a case where $\tau_{i}=\$ 18>\$ 14=\tau_{i}^{*}$. As in the previous examples, the agent's initial revised WTP with cheap talk is $\$ 6$. Again, letting $\alpha=0.5$ and $\gamma=0.25$, we see that with cheap talk $W T P_{i}^{1}=(0.75 \times 6)+(0.25 \times 18)=\$ 9$, with an anchoring effect of $\$ 9-\$ 6=\$ 3$. With no cheap talk, the agent's $W T P_{i}^{1}=(0.5 \times 10)+(0.5 \times 18)=\$ 14$, with an anchoring effect of $\$ 14-\$ 10=\$ 4$. In this case, we mistakenly conclude that cheap talk overcorrects for hypothetical bias (i.e., $\Delta_{i}=\$ 9-\$ 14=-\$ 5<-\mu=-\$ 4$ ).

\section{Experimental Design}

Here we describe a simple experimental design that distinguishes the effects of anchoring and cheap talk in the valuation of a public good. The design shares many of the traditional features of

\footnotetext{
${ }^{13}$ An interesting implication of this result is that samples with a substantial number of nay-sayers (i.e., low WTP individuals (Carson (2000))) will appear to be more often associated with effective cheap-talk scripts.
} 
public good experiments such as induced valuation and the incentive to free ride. ${ }^{14}$ Unlike many contingent valuation studies, we do not describe an actual nonmarket good. Instead, participants are investing in a generic public good which makes it easier to generalize our results to a wider range of nonmarket public goods. Valuation uncertainty $(\delta)$ is brought into the design by making the value of the public good random at each contribution level (discussed further below). The design is intended to mimic the way CV surveys for nonmarket goods are implemented in practice. The most common $\mathrm{CV}$ approach for eliciting the value of a nonmarket good is to present an individual with a take-it-or-leave-it choice at an announced price. The announced price is drawn from a pre-selected distribution in order to trace out the demand curve for the nonmarket good and to lessen the effects of anchoring to a single price. Consumers are generally comfortable with this type of binary choice at a fixed price as it closely resembles the daily purchasing decisions made for private goods. This binary choice environment is re-created in our experimental design, with subjects receiving different price announcements presented as take-it-or-leave-it choices.

We set up two treatments involving a hypothetical contribution toward a public good - one without cheap talk (NCT treatment) and one with cheap talk (CT treatment). The entire set of instructions and payout charts are included in Appendix B. As participants entered a classroom, they were given $\$ 10$ in cash to hypothetically "invest", an instruction page, and a page asking for an initial guess of their hypothetical investment decision. The instruction page, along with an example, were read aloud to the participants and any questions regarding the experiment were answered.

In the example, five people could invest between $\$ 0$ and $\$ 2$. Depending on their average investment and the roll of a die, the payout chart shows all the possible returns to an investment. After deciding an amount to invest, which could be $\$ 0$, thus placing the subject in the "No, I won’t

\footnotetext{
${ }^{14}$ For further details on public good experiments, see chapter two in the Handbook on Experimental Economics by Ledyard (1995).
} 
invest" section of the chart, a die was thrown to decide if the payout was the min (1 or 2 on the die), mid (3 or 4 ), or $\max (5$ or 6 ). If the total class investment was zero, payouts were zero to everyone. After the example chart was explained, subjects were then taken to the actual payout chart.

While the cooperative outcome to the investment game - everyone investing between $\$ 8$ and $\$ 10$ in the actual chart - results in the highest expected return, the noncooperative solution of no investment is the dominant strategy for all individuals. This captures the free-riding problem associated with public goods. Valuation uncertainty is captured by imposing a min, mid, and max payout range for each investment interval.

Participants in both treatments first completed a survey, which elicited a continuous measure of their initial WTPs for the actual payout chart. Participants were asked, "As an initial guess, how much of your $\$ 10$ do you think you would be willing to invest?" Answers were meant to capture the participant's initial WTP from their prior WTP distribution. This survey was then collected and a second questionnaire was distributed to everyone.

The second questionnaire elicited the participants' dichotomous investment choices. It asked a referendum question "Would you be willing to make an investment of \$xx?", where each participant was given a different selected $\$ \mathrm{xx}$ amount from the set of prices $\{\$ 1, \$ 3, \$ 5, \$ 7, \$ 9\} .{ }^{15}$ The referendum in the $\mathrm{CT}$ treatment was preceded by the following cheap-talk script:

Before answering the next question please note that in previous runs of this experiment we found that people typically overstate their true willingness to invest by

\footnotetext{
${ }^{15}$ Subjects were informed that not everyone in the group was receiving the same price but were not informed of the distribution of prices across players. In standard CV surveys, agents are given a randomized announced price but generally do not inquire about (and thus are not made aware of) the prices other respondents receive. This is because the cooperative nature of the public good game is not made explicit in field surveys, and because respondents complete the survey independently of one another, thus precluding the need to provide additional knowledge to respondents. The provision of this information represents a deviation from CV surveys in practice, but we do not feel that this alters the fundamental behavioral motives associated with hypothetical bias, cheap talk, and anchoring bias in our experiments.
} 
approximately $\$ 2.00$ when asked to do so in a hypothetical setting like this. Please keep

this in mind when answering the next question.

In each experimental treatment, the referendum was collected, the average class contributions were calculated, the die was rolled, hypothetical returns were announced and subjects were excused. The average class contributions in the NCT and CT treatments were $\$ 2.32$ and $\$ 1.67$, respectively. All sessions lasted between 10 and 15 minutes. Three sessions were conducted for each treatment; 20 to 30 subjects attended a session. Instructions are available upon request from the authors.

There was no deception involved in the cheap-talk script, which suggests individuals overestimated their true WTP by $\$ 2.00$. Prior to the CT and NCT sessions just described, we ran a smaller version of the NCT treatment, as well as a treatment where participants made actual investment decisions with the $\$ 10$. In the actual investment session participants made their referendum decision, we then collected their investment, rolled the die, calculated returns and paid them as they left the experiment. Each of the two sessions contained ten economics graduate students and resulted in an average investment of $\$ 2.40$ for the NCT session and an average contribution of $\$ 0.40$ in the actual investment treatment. This difference established the $\$ 2.00$ figure in the cheap talk statement above and provided evidence of positive and robust hypothetical bias.

\section{Econometric Analysis}

Our primary theoretical result is that anchoring bias and cheap talk interact in a nontrivial manner - one that makes standard econometric cheap-talk tests appear to be effective for relatively high announced prices and ineffective for relatively low announced prices. In this section, we directly test this hypothesis using the experimental data. The results support our theory; when the sample is split by announced prices, cheap talk appears effective for those receiving relatively high prices 
and appears ineffective for those receiving relatively low prices.

Selected descriptive statistics for the experimental data are provided in Table 1 . These are based in part on the demographic surveys completed by subjects. As Table 1 indicates, the average initial willingness to pay $\left(W T P^{0}\right)$ is $\$ 3.67$, while the average referendum investment amount $(\tau)$ is $\$ 4.95$ with $48 \%$ of respondents saying "yes" to the investment question. At the bottom of Table 1 we break down the referendum responses and $W T P^{0}$ by referendum investment amounts. Although the proportion of "Yes" responses tends to fall as the investment amount increases, it is not uniform. For example, in moving from a $\$ 5$ to a $\$ 7$ referendum price, the proportion of individuals responding "Yes" to the investment question actually increased. Notice, however, that the $\$ 7$ group had a significantly higher initial WTP, indicating that this group started the experiment with an increased willingness to invest. This further reinforces the need to consider announced prices relative to initial WTP. There is also a nearly even split in each treatment, with $54 \%$ receiving cheap talk (CT) and $46 \%$ receiving no cheap talk (NCT). Finally, $58 \%$ of our sample received a relatively high announced price $\left(\tau>W T P^{0}\right)$ while $32 \%$ received a relatively low announced price $\left(\tau<W T P^{0}\right)$.

\subsection{Econometric Methods}

As is common in the cheap-talk literature, we specify an empirical model for the (latent) $W T P_{i}^{1}$ variable which allows us to estimate a constant cheap-talk and anchoring coefficients ${ }^{16}$

$$
W T P_{i}^{1}=W T P_{i}^{0}+\Delta C_{i}+\beta_{\tau} \tau_{i}+\epsilon_{i}
$$

\footnotetext{
${ }^{16}$ Recall that the cheap-talk meaure $\Delta_{i}$ in (13) varies across all agents. Here, we are interested in specifying an estimable equation with a constant cheap-talk coefficient, $\Delta$, that is similar to that commonly estimated in the literature and that will enable us to highlight the biases associated with failing to recognize the interaction between cheap talk and anchoring. Also, note that although $\Delta_{i}$ in (13) is defined as the difference between expected values (with and without cheap talk) for the same agent, the econometric analysis will contrast the expected WTP of one set of agents that receive cheap talk (treatment group) with a different set of agents that do not receive cheap talk (control group), holding all other observable factors constant.
} 
where $i=1, \ldots, N$ indexes individual observations, $W T P_{i}^{0}$ is a continuous initial measure of WTP, $\epsilon_{i}$ is an i.i.d. normally distributed error term with a zero mean and variance $\sigma_{\epsilon}^{2}, C_{i}$ is a dummy variable set equal to one if the $i^{\text {th }}$ agent receives cheap talk and zero otherwise, and $\Delta$ and $\beta_{\tau}$ are parameters capturing potential cheap-talk and anchoring effects, respectively. ${ }^{17}$ We then define the binary variable $A C C E P T_{i}$, which equals one if the agent invests at his or her given investment level $\tau_{i}$, and zero otherwise. As is standard in the literature, we assume that $A C C E P T_{i}=1$ responses imply $W T P_{i}^{1}>\tau_{i}$ and $A C C E P T_{i}=0$ responses imply $W T P_{i}^{1} \leq \tau_{i}$.

Next, we define the necessary probabilities for maximum-likelihood estimation. Using (15), the probability that agent $i$ will accept bid $\tau_{i}$ is

$$
\begin{aligned}
P_{i} & =\operatorname{Pr}\left[A C C E P T_{i}=1\right] \\
& =\operatorname{Pr}\left[W T P_{i}^{1}>\tau_{i}\right] \\
& =\operatorname{Pr}\left[\epsilon_{i}>-W T P_{i}^{0}-\Delta C_{i}+\left(1-\beta_{\tau}\right) \tau_{i}\right] \\
& =\Phi\left(\frac{1}{\sigma_{\epsilon}}\left[W T P_{i}^{0}+\Delta C_{i}-\left(1-\beta_{\tau}\right) \tau_{i}\right]\right)
\end{aligned}
$$

for $i=1, \ldots, N$, where $\Phi$ is the standard normal cumulative density function. A significant advantage of specifying a model such as (15) with prior WTP as an explanatory variable is that it allows identification of the fundamental cheap talk and anchoring parameters. The logic here is similar to that in Cameron and James (1987), but rather than using $\tau_{i}$ to identify $\sigma_{\epsilon}$, it is accomplished using the variation in $W T P_{i}^{0}$. Without incorporating $W T P_{i}^{0}$ into the determination of revised WTP, it would not be possible to identify the fundamental anchoring parameter $\beta_{\tau}$. The

\footnotetext{
${ }^{17}$ As pointed out by an anonymous reviewer, responses to open-ended WTP questions are governed by different incentive compatibility properties than responses to referendum questions. As such, one should exercise caution when using open-ended questions to guide responses to referendum questions. The extent to which the initial openended question might alter the agent's response to cheap talk and the subsequent referendum question is an open and interesting research question.
} 
associated log likelihood function is

$$
\log L=\sum_{i=1}^{N}\left\{A C C E P T_{i} \ln \left(P_{i}\right)+\left(1-A C C E P T_{i}\right) \ln \left(1-P_{i}\right)\right\}
$$

As mentioned in the introduction, the existing cheap-talk literature reports mixed results regarding estimates of $\Delta$. Some studies have found that cheap talk is effective (i.e., estimates of $\Delta$ are negative and statistically significant), while others have found estimates of $\Delta$ that are statistically indistinguishable from zero or possibly even positive. Based on our theory, estimates of $\Delta$ from equation (15) are likely to be biased because they do not account for the interaction of anchoring with cheap talk. As highlighted in Regions 1 and 3 of Figure 2, if $W T P_{i}^{0}<(>) \tau_{i}$ we expect estimates of $\Delta$ will be biased upward (downward) in magnitude.

To explore this possibility, we partition our sample into those who made investment decisions at relatively low announced prices $\left(L P_{i}=1\right.$ if $\tau_{i}<W T P_{i}^{0}$; zero otherwise $)$ and those who made investment decisions at relatively high announced prices $\left(H P_{i}=1\right.$ if $\tau_{i}>W T P_{i}^{0}$; zero otherwise). We then modify equation (15) allowing for two cheap talk effects - one for relatively low announced prices and one for relatively high announced prices:

$$
W T P_{i}^{1}=W T P_{i}^{0}+\Delta_{H i g h}\left(C_{i} \times H P_{i}\right)+\Delta_{L o w}\left(C_{i} \times L P_{i}\right)+\beta_{\tau} \tau_{i}+\epsilon_{i}
$$

Our theory predicts that the estimate for the high-price individuals $\left(\Delta_{H i g h}\right)$ will be negative and of greater magnitude than the estimate for the low-price individuals $\left(\Delta_{\text {Low }}\right)$.

\subsection{Econometric Results}

We present our econometric results in Table 2. Models 1 and 2 estimate the effect of cheap talk on WTP using an interval regression model. An interval regression is simply an ordered probit 
model with fixed and known cut points (Woolridge (2002), page 509). Model 1 does so for the full sample, while model 2 splits the cheap talk effect into a relatively high-price and low-price categories. As discussed above, an important advantage of the specification in equation (18) is that all the fundamental parameters in Models 1 and 2, including the anchoring parameter, are identifiable. In fact, there is evidence of statistically significant anchoring, in the neighborhood of one-third of initial WTP. Turning to the cheap-talk effects, we note that the cheap-talk coefficient in model 1, while negative, is not statistically different than zero. As mentioned in Section 1, this is consistent with much of the recent cheap-talk literature, which finds that short-scripted cheap talk is ineffective. Most importantly for this study, in model 2 cheap talk is effective (negative and statistically significant) for those receiving relatively high announced prices and ineffective (positive and statistically insignificant) for those receiving low announced prices. These results support our hypotheses as shown in Regions 1, 2 and 3 of Figure 2, and, as mentioned in Section 1, are consistent three recent papers in the cheap talk literature - Brown, Azjen and Hrubes (2003); Murphy, Stevens and Weatherhead (2005) and Cherry and Whitehead (forthcoming). All three papers report that cheap talk is effective at relatively high announced prices but ineffective at low announced prices. ${ }^{18}$

\section{DBDC Formats and Incentive Incompatibility}

Although the Bayesian-updating process described in Section 2.2 is based on the single-bounded dichotomous-choice format, our framework naturally extends to multiple-bounded dichotomouschoice formats. For example, in a double-bounded format the agent receives the signal $s_{i}=$

\footnotetext{
${ }^{18}$ We also estimated $W T P$ controlling for the demographic variables elicited on the last page of the experiment (see Appendix B). The control variables include age, gender, income, college GPA, college rank and degree of risk aversion. The observed heterogeneity associated with these variables was not capable of explaining the willingness to invest in the public good. Most of the coefficient estimates associated with the demographic variables were statistically insignificant and did not qualitatively change the estimates of the anchoring and cheap-talk parameters.
} 
$\left\{c_{i}, \tau_{1 i}, \tau_{2 i}\right\}$ sequentially from the interviewer, where $\tau_{1 i}$ and $\tau_{2 i}$ represent the initial and followup announced prices, respectively. In this case, the agent uses Bayes' formula twice to update beliefs regarding the distribution of $\delta_{i}$ - first using (8) based solely on $c_{i}$ and $\tau_{1 i}$, followed by a revision of beliefs again using (8) but based instead on $c_{i}, \tau_{1 i}$ and $\tau_{2 i}$. The agent then forms sequentially updated expectations of $\delta_{i}$ using (9). In a technical appendix, available upon request, we form a measure of cheap-talk effectiveness similar to that presented in Section 2.2, and distinguish the cases based on the relative values of the anchoring parameters, $W T P_{i}^{0}, \tau_{1 i}$ and $\tau_{2 i}$.

In the context of the double-bounded dichotomous-choice (DBDC) format, the question of incentive incompatibility arises. ${ }^{19}$ Do the follow-up bids induce a "structural shift" in the agent's stated WTP away from the underlying true WTP (in either the positive or negative direction)? Previous studies laying out the theoretical underpinnings of this question include Alberini, Kanninen and Carson (1997) and Carson, Groves and Machina (1999). Whitehead (2002) finds empirical evidence in support of the existence of incentive incompatibility in the double-bounded format. Whitehead presumes that the agent's initial WTP represents the true underlying WTP. As a result, any shift away from initial WTP induced through the iterative bidding process represents perforce incentive incompatibility. However, for most goods in which CV analysis is applied, agents are unlikely to know their true WTP with certainty. Recall from (5) that $W T P_{i}^{0}$ represents the agent's perception of the true WTP rather than true WTP itself. Therefore, the shift from $W T P_{i}^{0}$ to $W T P_{i}^{1}$ represents the agent's rational updating of the uncertainty associated with what is believed to be the true WTP. In an environment of uncertainty, it is possible that the follow-up referenda in DBDC formats provide valuable information for agents who are rationally seeking their true WTP.

\footnotetext{
${ }^{19}$ The early literature on incentive incompatibility in CV studies (Cummings, Elliot, Harrison and Murphy (1997); Cummings, Harrison and Rutstrom (1995)) appears to characterize incentive incompatibility more broadly than some of the more recent studies. For example, Cummings, Harrison and Rutstrom (1995) on page 260 state that incentive compatibility "implies that subjects will answer the CVM's hypothetical question in the same way as they would answer an identical question asking for a real committment." While Whitehead (2002) in a more recent study states on page 287 that in DBDC formats "if the follow-up questions are not incentive compatible, stated willingness to pay will be based on true willingness to pay with a shift parameter."
} 
Whether this updating brings the agent closer to the true WTP or not depends on the information contained in the signal. Once this Bayesian perspective of WTP formation is taken, the recent discussion of the incentive incompatibility of DBDC formats changes markedly.

\section{Summary}

In this paper, we develop a Bayesian approach to model the elicitation of WTP for nonmarket goods and services in the presence of agent uncertainty and noisy signaling. Agents generally have limited experience in trying to formulate precise values for the types of public goods typically examined in $\mathrm{CV}$ studies. In these situations, it seems natural to model WTP as being derived from a Bayesian-updating process rather than from a deterministic process. In a Bayesian framework, agents begin with a prior distribution over their uncertain WTP and use this distribution to form an initial WTP estimate. Agents are then provided with signals from the interviewer such as announced prices and cheap-talk scripts. This information is used by agents to update their priors as they "grope" for their true WTP.

One important implication of this process is that, from an econometric standpoint, the signals interact in such a way as to bias their respective measured effects. As we find in this paper, the direction and magnitude of the bias in dichotomous-choice formats depends on the distribution of initial WTPs relative to the opening prices. Within the context of a CV survey, where the signals are an announced opening price and cheap talk, we show that if the price is high relative to an agent's initial WTP, then standard econometric methods are likely to find a significant or exacerbated cheap-talk effect. A price that is low relative to an agent's initial WTP leads to a measured cheap-talk effect that is mitigated, non-existent, or even counterintuitive. Because agents' initial WTPs are typically unknown in nonmarket valuation studies, it is difficult a priori to predict the direction and magnitude of the potential bias. We also emphasize that our theory 
predicts that the bias in measuring the cheap-talk effect depends on the announced price relative to the respondent's initial WTP, not simply relative to the average announced price. While these two measures are likely to be positively correlated, there are also likely to be instances where they lead one to draw quite different conclusions.

We present two sources of information to test our theory. First, we find that our Bayesian model is supported in an experimental setting, where we control for external influences. When the experimental data are split into relatively high and low announced prices, cheap talk appears effective for high prices and ineffective for low prices. Second, we highlight recent work by Brown et al. (2003), Murphy et al. (2005), and Cherry and Whitehead (forthcoming) concluding that cheap-talk effects are weak, but as predicted by our theory it appears effective for those receiving relatively high announced prices and ineffective for those receiving relatively low announced prices. We interpret this research as being consistent with the interaction between anchoring and cheap talk in a Bayesian-updating framework. Taken together, neither of the two sets of evidence allow us to reject our theory. Consequently, our Bayesian interpretation of how agents value public goods in the presence of uncertainty and noisy signaling is a plausible interpretation of reality.

In light of our findings, what steps might be taken in future empirical research to avoid biasing the measurement of signals such as cheap talk CV studies? One obvious option is to revert to an open-ended question format for eliciting WTP so that the issue of anchoring is moot. The referendum format, however, is currently preferred by CV practitioners over the open-ended format and has the recommendation of the NOAA panel because of its conformity with real market circumstances (Arrow, Solow, Portney, Leamer, Radner and Schuman (1993)). Therefore, assuming the referendum format remains the preferred approach, we suggest that anchoring to the bid should be explicitly modeled and accounted for in estimation, as we have shown in this paper.

To follow this approach, and maintain consistency with a Bayesian-updating interpretation, es- 
timates of initial WTP need to be elicited prior to the referendum question. In our CV application, we have suggested using an open-ended format question to elicit this initial value (reversing the question order in Green, Jacowitz, Kahneman and McFadden (1998), who ask an initial referendum question with a follow-up open-ended question), although other question formats may be possible. As shown in this paper, obtaining information about initial WTP allows for joint identification of the scaling, cheap talk and anchoring parameters. This approach stands in stark contrast to previous research that either does not allow for anchoring (e.g., Cameron and James (1987)) or treats anchoring as occurring only for the follow-up question in a double-bounded dichotomous choice framework (e.g., Whitehead (2002)).

Finally, our framework is applicable to more than just CV surveys for public goods. Marketing questionnaires about WTP for a hypothetical product based on prices of currently sold products are a close relative to the CV survey. However, any situation where agents are provided information, either before or during the elicitation of subjective numerical values, or asked to give a yes or no answer, fits our theoretical setup. The provided information need not be verifiable or credible. All that is necessary is that agents think the signal might help them make a better guess. Persons then rationally update their priors using the new information.

Since WTP in a CV survey is just a statement of preference, it is easy to see how our theory extends to other types of surveys. Political opinion polls solicit voter preferences and approval ratings, for which the yes or no question is frequently preceded by information from the pollster, or a headline event in the media. There are many surveys that create a consensus forecast or estimate consumer confidence based on recent past trends or other information. Asking for a forecast or a feeling of confidence is similar in spirit to asking for WTP. For the most part, all surveys ask for responses that can be numerically coded for analysis and are seldom answered with perfect certainty. In these cases, where agents can receive multiple, sequential signals prior to stating 
their preferences, our theory will help researchers accurately measure the effects of information signals during the value-elicitation process.

\section{References}

Aadland, D. and Caplan, A. J.: 2003, Willingness to pay for curbside recycling with detection and mitigation of hypothetical bias, American Journal of Agricultural Economics 85(2), 492-502.

Aadland, D. and Caplan, A. J.: 2006, Cheap talk reconsidered: Evidence from cvm, Journal of Economics and Behavioral Organization 60(4), 562-578.

Adamowicz, W., Louviere, J. and Williams, M.: 1994, Combining revealed and stated preference methods for valuing enviromental amenities, Journal of Environmental Economics and Management 26, 271-292.

Alberini, A., Kanninen, B. and Carson, R. T.: 1997, Modeling response incentive effects in dichotomous choice contingent valuation data, Land Economics 73(3), 309-324.

Anderson, L. R. and Holt, C. A.: 1997, Information cascades in the laboratory, American Economic Review 87(5), 847-862.

Armantier, O.: 2006, Estimates of own lethal risks and anchoring effects, Journal of Risk and Uncertainty 32(1), 37-56.

Arrow, K., Solow, R., Portney, P. R., Leamer, E. E., Radner, R. and Schuman, H.: 1993, Report of the noaa panel on contingent valuation, Federal Register 58(10), 4601-4614.

Bernheim, D.: 1994, A theory of conformity, Journal of Political Economy 102, 841-877.

Brookshire, D. S., Thayer, M. A., Schulze, W. D. and D'Arge, R. C.: 1982, Valuing public goods: a comparison of survey and hedonic approaches, American Economic Review 72(1), 165-177. 
Brown, T. C., Azjen, I. and Hrubes, D.: 2003, Further tests of entreaties to avoid hypothetical bias in referendum contingent valuation, Journal of Environmental Economics and Management 46, 353-361.

Cameron, T. A.: 2005, Updating subjective risks in the presence of conflicting information: An application to climate change, Journal of Risk and Uncertainty 30(1), 63-97.

Cameron, T. A. and James, M. D.: 1987, Efficient estimation methods for close-ended contingent valuation surveys, Review of Economics and Statistics 69, 269-276.

Carlsson, F., Frykblom, P. and Lagerkvist, C. J.: 2005, Using cheap talk as a test of validity in choice experiments, Economics Letters 89, 147-152.

Carson, R. T.: 2000, Contingent valuation: A user's guide, Environmental Science and Technology 34(8), 1413-1418.

Carson, R. T., Groves, T. and Machina, M. J.: 1999, Incentive and informational properties of preference questions. Plenary address, European Association of Environmental and Resoruce Economists, Oslo, Norway.

Chanel, O., Aprahamian, F. and Luchini, S.: forthcoming, Modeling starting point bias as unobserved heterogeneity in contingent valuation surveys: an application to air pollution, American Journal of Agricultural Economics .

Cherry, T. L. and Whitehead, J.: forthcoming, The cheap-talk protocol and the estimation of the benefits of wind power, Resource and Energy Economics .

Cummings, R. G., Brookshire, D. S. and Schulze, W. D. (eds): 1986, Valuing Environmental Goods: A State of the Arts Assessment of the Contingent Valuation Method, Rowman and Allanheld. 
Cummings, R. G., Elliot, S., Harrison, G. W. and Murphy, J.: 1997, Are hypothetical referenda incentive compatible?, Journal of Political Economy 105(3), 609-621.

Cummings, R. G., Harrison, G. W. and Rutstrom, E. E.: 1995, Homegrown values and hypothetical surveys: is the dichotomous choice approach incentive compatible?, American Economic Review 85(1), 260-266.

Cummings, R. G., Harrison, G. W. and Taylor, L. O.: 1995, Can the bias of contingent valuation surveys be reduced? evidence from the laboratory. unpublished manuscript, Division of Research, College of Business Administration, University of South Carolina.

Cummings, R. G. and Taylor, L. O.: 1999, Unbiased value estimates for environmental goods: A cheap talk design for the contingent valuation method, American Economic Review 89(3), 649666.

Gibbons, R.: 1992, p.210, Game Theory for Applied Economists, Princeton University Press: Princeton, NJ.

Green, D., Jacowitz, K. E., Kahneman, D. and McFadden, D.: 1998, Referendum contingent valuation, anchoring, and willingness to pay for public goods, Resource and Energy Economics $\mathbf{2 0}(2), 85-116$.

Hausman, J. A.: 1993, Contingent Valuation: A Critical Assessment, North Holland; Amsterdam.

Herriges, J. A. and Shogren, J. F.: 1996, Starting point bias in dichotomous choice valuation with follow-up questioning, Journal of Environmental Economics and Management 30, 112-131.

Hogg, R. V. and Craig, A. T.: 1978, Introduction to Mathematical Statistics, MacMillan Publishing, New York, New York. 
Hurd, M. D.: 1999, Anchoring and acquiescence bias in measuring assets in household surveys, Journal of Risk and Uncertainty 19(1), 111-136.

Johannesson, M., Blomquist, G. C., Blumenschein, K., Johansson, P.-O., Liljas, B. and O’Conor, R. M.: 1999, Calibrating hypothetical willingness to pay responses, Journal of Risk and Uncertainty 8, 21-32.

Kahneman, D. and Knetsch, J. L.: 1992, Valuing public goods: The purchase of moral satisfaction, Journal of Environmental Economics and Management 22, 57-70.

Laibson, D. and Zeckhauser, R.: 1998, Amos tversky and the ascent of behavioral economics, Journal of Risk and Uncertainty 16, 7-47.

Ledyard, J. O.: 1995, Public goods: A survey of experimental research, in J. H. Kagel and A. E. Roth (eds), The Handbook of Experimental Economics, Princeton University Press.

List, J. A.: 2001, Do explicit warnings eliminate the hypothetical bias in elicitation procedures? evidence from field auction experiments, American Economic Review 91(5), 1498-1507.

Loomis, J. B., Gonzalez-Caban, A. and Gregory, R.: 1994, Do reminders of substitutes and budget constraints influence contingent valuation estimates?, Land Economics 70(4), 499-506.

Lusk, J. L.: 2003, Effects of cheap talk on consumer willingness-to-pay for golden rice, American Journal of Agricultural Economics 85(4), 840-856.

McFadden, D.: 2001, Economic choices, American Economic Review 91(3), 351-378.

McLeod, D. M. and Bergland, O.: 1999, Willingness-to-pay estimates using double-bounded dichotomous-choice contingent valuation format: A test for validity and precision in a bayesian framework, Land Economics 75(1), 115-125. 
Mitchell, R. C. and Carson, R. T.: 1989, Using surveys to value public goods: The contingent valuation method. unpublished manuscript, Resources for the Future, Washington D.C.

Murphy, J. J., Allen, P. G., Stevens, T. and Weatherhead, D.: forthcoming, A meta-analysis of hypothetical bias in stated preference valuation, Environmental and Resource Economics .

Murphy, J. J., Stevens, T. and Weatherhead, D.: 2005, Is cheap talk effective at eliminating hypothetical bias in a provision point mechanism?, Environmental and Resource Economics 30(3), 327-343.

Neil, H.: 1995, The context for substitutes in cvm studies: some empirical observations, Journal of Environmental Economics and Management 29, 393-397.

Poe, G. L., Clark, J. E., Rondeau, D. and Schulze, W. D.: 2002, Provision point mechansims and field validity tests of contingent valuation, Environmental and Resource Economics 23, 105131.

Tversky, A. and Kahneman, D.: 1974, Judgement under uncertainty, Science 185, 1122-1131.

Viscusi, W. K. and O'Connor, C. J.: 1984, Adaptive responses to chemical labeling: Are workers bayesian decision makers?, American Economic Review 74(5), 942-956.

Whitehead, J. C.: 2002, Incentive incompatibility and starting-point bias in iterative valuation questions, Land Economics 78(2), 285-297.

Woolridge, J. M.: 2002, Econometric Analysis of Cross Section and Panel Data, The MIT Press; Cambridge, MA. 


\section{Appendix A. Derivation of the Bayesian Weighted-Average Updating Function}

Start by considering Bayes' formula

$$
k(W T P \mid \tau) \propto g(\tau \mid W T P) h(W T P)
$$

where $\propto$ stands for "proportional to" as the marginal distribution for $\tau$ is dropped. This is standard in Bayesian analysis. Now let the conditional and prior distributions be

$$
\begin{aligned}
g(\tau \mid W T P) & \sim N\left(W T P, \sigma_{g}^{2}\right)=\frac{1}{\sqrt{2 \pi} \sigma_{g}} \exp \left[\frac{-(\tau-W T P)^{2}}{2 \sigma_{g}^{2}}\right] \\
h(W T P) & \sim N\left(W T P_{0}, \sigma_{h}^{2}\right)=\frac{1}{\sqrt{2 \pi} \sigma_{h}} \exp \left[\frac{-\left(W T P-W T P_{0}\right)^{2}}{2 \sigma_{h}^{2}}\right] .
\end{aligned}
$$

The posterior distribution is then

$$
k(W T P \mid \tau) \propto \frac{1}{2 \pi \sigma_{g} \sigma_{h}} \exp \left[-\frac{(\tau-W T P)^{2}}{2 \sigma_{g}^{2}}-\frac{\left(W T P-W T P_{0}\right)^{2}}{2 \sigma_{h}^{2}}\right],
$$

which after expanding the squared terms and dropping constants gives

$$
k(W T P \mid \tau) \propto \exp \left[-\frac{W T P^{2}\left(\sigma_{g}^{2}+\sigma_{h}^{2}\right)+W T P\left(-2 \tau \sigma_{h}^{2}-2 W T P_{0} \sigma_{g}^{2}\right)}{2 \sigma_{g}^{2} \sigma_{h}^{2}}\right] .
$$

Finally, we complete the square in $W T P$ to get

$$
k(W T P \mid \tau) \propto \exp \left[-\frac{\left(W T P-\frac{\tau \sigma_{h}^{2}+W T P_{0} \sigma_{g}^{2}}{\sigma_{g}^{2}+\sigma_{h}^{2}}\right)^{2}}{\frac{2 \sigma_{g}^{2} \sigma_{h}^{2}}{\sigma_{g}^{2}+\sigma_{h}^{2}}}\right] .
$$


This implies that the mean of the posterior distribution (or the updated WTP value) is

$$
E(W T P \mid \tau)=\frac{\tau \sigma_{h}^{2}+W T P_{0} \sigma_{g}^{2}}{\sigma_{g}^{2}+\sigma_{h}^{2}}=\left[\frac{\sigma_{h}^{2}}{\sigma_{g}^{2}+\sigma_{h}^{2}}\right] \tau+\left[\frac{\sigma_{g}^{2}}{\sigma_{g}^{2}+\sigma_{h}^{2}}\right] W T P_{0}
$$

which if we define $\alpha=\sigma_{h}^{2} /\left(\sigma_{g}^{2}+\sigma_{h}^{2}\right)$, can be written as

$$
W T P_{1}=\alpha \tau+(1-\alpha) W T P_{0}
$$




\section{Appendix B. Experimental Instructions for NCT and CT Treatments}

\section{Instructions}

This is an experiment on how people make investment decisions. There are no right or wrong decisions. You have been given $\$ 10$ to participate. This is yours to keep. You will not be paid anything more. Before the experiment begins, an example of how the experiment works is described. The actual experiment will be conducted after going through this example.

Suppose there are five people, each of whom is given $\$ 2$ that he or she can invest. The individuals have made the following decisions:

- Person \#1 - Invests nothing.

- Persons \#2 and \#3 - Invest \$1 each.

- Persons \#4 and \#5 - Invest \$2 each.

This results in a total of $\$ 6$ invested from the five people, for an average investment of $\$ 6 \div 5$ individuals $=\$ 1.20$. Using the table below, we can now calculate the return on the investment for each person.

PAYOUT CHART - THIS IS ONLY AN EXAMPLE

\begin{tabular}{|c|c|c|c|c|c|c|}
\hline \multirow{2}{*}{$\begin{array}{c}\text { Average } \\
\begin{array}{c}\text { Group } \\
\text { Investment }\end{array}\end{array}$} & \multicolumn{4}{|c|}{ Range of Payouts Based on Your Investment Choice } \\
\cline { 2 - 6 } & \multicolumn{3}{|c|}{ "YES, I'll invest” } & \multicolumn{3}{c|}{ "NO, I won't invest” } \\
\cline { 2 - 7 } & $\begin{array}{c}\text { Min } \\
\text { Payout }\end{array}$ & $\begin{array}{c}\text { Mid } \\
\text { Payout }\end{array}$ & $\begin{array}{c}\text { Max } \\
\text { Payout }\end{array}$ & $\begin{array}{c}\text { Min } \\
\text { Payout }\end{array}$ & $\begin{array}{c}\text { Mid } \\
\text { Payout }\end{array}$ & $\begin{array}{c}\text { Max } \\
\text { Payout }\end{array}$ \\
\hline $\begin{array}{c}\text { Greater than \$0; } \\
\text { Less than or equal to \$1 }\end{array}$ & $\$ 0$ & $\$ 1$ & $\$ 2$ & $\$ 1$ & $\$ 2$ & $\$ 3$ \\
\hline $\begin{array}{c}\text { Greater than \$1; } \\
\text { Less than or equal to \$2 }\end{array}$ & $\$ 1$ & $\$ 2$ & $\$ 3$ & $\$ 2$ & $\$ 3$ & $\$ 4$ \\
\hline
\end{tabular}

Begin by noting that each person's payout range is determined in part by his or her investment choice and the average investment of the group. The average investment of $\$ 1.20$ falls between $\$ 1$ and $\$ 2$ so we can focus on the second row of numbers in the table. The exact payout is then determined by the roll of a die. The roll of the die gives equal chances to the Min, Mid and Max payouts. For both the "YES" and "NO" columns, if a 1 or 2 is rolled the Min is paid; if a 3 or 4 is rolled the Mid is paid; and if a 5 or 6 is rolled the Max is paid.

For example, assume a “3” is rolled, so the Mid payout occurs. Person \#1 invested nothing. The average group investment was $\$ 1.20$. Therefore, the person receives a final payout of \$3 (\$3 payout less $\$ 0$ invested). Persons \#2 and \#3 each invested $\$ 1$. They receive a payout of $\$ 2$, and their net return is $\$ 1$ (\$2 payout less \$1 invested). Persons \#4 and \#5 each invested \$2 and also receive a final payout of $\$ 2$. Their net return is zero.

Are there any questions before we begin? 


\section{Experiment}

Directions. Use the payout chart below to decide whether to hypothetically invest all, part, or none of your $\$ 10$. If this experiment were for real, your payout range would determined by your investment choice and the average investment of the group. (Note that if the total group investment is zero, the payout is zero to everyone.) The exact payout would be determined by the roll of a die. For both the YES and NO columns, if a 1 or 2 is rolled the Min is paid; if a 3 or 4 is rolled the Mid is paid; and if a 5 or 6 is rolled the Max is paid.

\section{PAYOUT CHART}

\begin{tabular}{|c|c|c|c|c|c|c|}
\hline \multirow{3}{*}{$\begin{array}{c}\text { Average } \\
\text { Group } \\
\text { Investment }\end{array}$} & \multicolumn{6}{|c|}{ Range of Payouts Based on Your Investment Choice } \\
\hline & \multicolumn{3}{|c|}{ “YES, I’ll invest” } & \multicolumn{3}{|c|}{ “NO, I won’t invest” } \\
\hline & $\begin{array}{l}\text { Min } \\
\text { Payout }\end{array}$ & $\begin{array}{c}\text { Mid } \\
\text { Payout }\end{array}$ & $\begin{array}{c}\text { Max } \\
\text { Payout }\end{array}$ & $\begin{array}{c}\text { Min } \\
\text { Payout }\end{array}$ & $\begin{array}{c}\text { Mid } \\
\text { Payout }\end{array}$ & $\begin{array}{l}\text { Max } \\
\text { Payout }\end{array}$ \\
\hline $\begin{array}{c}\text { Greater than } \$ 0 ; \\
\text { Less than or equal to } \$ 2\end{array}$ & $\$ 0$ & $\$ 1$ & $\$ 2$ & $\$ 1$ & $\$ 2$ & $\$ 3$ \\
\hline $\begin{array}{c}\text { Greater than } \$ 2 ; \\
\text { Less than or equal to } \$ 4\end{array}$ & $\$ 3$ & $\$ 4$ & $\$ 5$ & $\$ 4$ & $\$ 5$ & $\$ 6$ \\
\hline $\begin{array}{c}\text { Greater than } \$ 4 ; \\
\text { Less than or equal to } \$ 6\end{array}$ & $\$ 6$ & $\$ 7$ & $\$ 8$ & $\$ 7$ & $\$ 8$ & $\$ 9$ \\
\hline $\begin{array}{c}\text { Greater than } \$ 6 \text {; } \\
\text { Less than or equal to } \$ 8\end{array}$ & $\$ 9$ & $\$ 10$ & $\$ 11$ & $\$ 10$ & $\$ 11$ & $\$ 12$ \\
\hline $\begin{array}{c}\text { Greater than } \$ 8 ; \\
\text { Less than or equal to } \$ 10\end{array}$ & $\$ 12$ & $\$ 13$ & $\$ 14$ & $\$ 13$ & $\$ 14$ & $\$ 15$ \\
\hline
\end{tabular}

\section{QUESTION \#1}

As an initial guess, how much of your $\$ 10$ do you think you'd be willing to invest? 


\section{(No Cheap Talk) Experiment (page 2)}

The payout chart below is reproduced from the previous page in order to help you answer the following question.

\section{PAYOUT CHART}

\begin{tabular}{|c|c|c|c|c|c|c|}
\hline \multirow{2}{*}{$\begin{array}{c}\text { Average } \\
\text { Group } \\
\text { Investment }\end{array}$} & \multicolumn{5}{|c|}{ Range of Payouts Based on Your Investment Choice } \\
\cline { 2 - 6 } “YES”, I'll invest. & \multicolumn{3}{c|}{ “NO”, I won't invest. } \\
\cline { 2 - 7 } & $\begin{array}{c}\text { Min } \\
\text { Payout }\end{array}$ & $\begin{array}{c}\text { Mid } \\
\text { Payout }\end{array}$ & $\begin{array}{c}\text { Max } \\
\text { Payout }\end{array}$ & $\begin{array}{c}\text { Min } \\
\text { Payout }\end{array}$ & $\begin{array}{c}\text { Mid } \\
\text { Payout }\end{array}$ & $\begin{array}{c}\text { Max } \\
\text { Payout }\end{array}$ \\
\hline $\begin{array}{c}\text { Greater than \$0; } \\
\text { Less than or equal to \$2 }\end{array}$ & $\$ 0$ & $\$ 1$ & $\$ 2$ & $\$ 1$ & $\$ 2$ & $\$ 3$ \\
\hline $\begin{array}{c}\text { Greater than \$2; } \\
\text { Less than or equal to \$4 }\end{array}$ & $\$ 3$ & $\$ 4$ & $\$ 5$ & $\$ 4$ & $\$ 5$ & $\$ 6$ \\
\hline $\begin{array}{c}\text { Greater than \$4; } \\
\text { Less than or equal to \$6 }\end{array}$ & $\$ 6$ & $\$ 7$ & $\$ 8$ & $\$ 7$ & $\$ 8$ & $\$ 9$ \\
\hline $\begin{array}{c}\text { Greater than \$6; } \\
\text { Less than or equal to \$8 }\end{array}$ & $\$ 9$ & $\$ 10$ & $\$ 11$ & $\$ 10$ & $\$ 11$ & $\$ 12$ \\
\hline $\begin{array}{c}\text { Greater than \$8; } \\
\text { Less than or equal to \$10 }\end{array}$ & $\$ 12$ & $\$ 13$ & $\$ 14$ & $\$ 13$ & $\$ 14$ & $\$ 15$ \\
\hline
\end{tabular}

\section{QUESTION \#2.}

This question requires a choice for which you would be hypothetically paid based on your answer.

Would you be willing to make an investment of $\mathbf{x x}$ dollars?

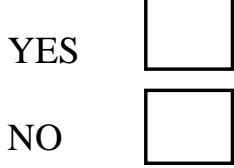




\section{(Cheap Talk) Experiment (page 2)}

The payout chart below is reproduced from the previous page in order to help you answer the following question.

\section{PAYOUT CHART}

\begin{tabular}{|c|c|c|c|c|c|c|}
\hline \multirow{2}{*}{$\begin{array}{c}\text { Average } \\
\text { Group } \\
\text { Investment }\end{array}$} & \multicolumn{5}{|c|}{ Range of Payouts Based on Your Investment Choice } \\
\cline { 2 - 6 } “YES”, I'll invest. & \multicolumn{3}{c|}{ “NO”, I won't invest. } \\
\cline { 2 - 7 } & $\begin{array}{c}\text { Min } \\
\text { Payout }\end{array}$ & $\begin{array}{c}\text { Mid } \\
\text { Payout }\end{array}$ & $\begin{array}{c}\text { Max } \\
\text { Payout }\end{array}$ & $\begin{array}{c}\text { Min } \\
\text { Payout }\end{array}$ & $\begin{array}{c}\text { Mid } \\
\text { Payout }\end{array}$ & $\begin{array}{c}\text { Max } \\
\text { Payout }\end{array}$ \\
\hline $\begin{array}{c}\text { Greater than \$0; } \\
\text { Less than or equal to \$2 }\end{array}$ & $\$ 0$ & $\$ 1$ & $\$ 2$ & $\$ 1$ & $\$ 2$ & $\$ 3$ \\
\hline $\begin{array}{c}\text { Greater than \$2; } \\
\text { Less than or equal to \$4 }\end{array}$ & $\$ 3$ & $\$ 4$ & $\$ 5$ & $\$ 4$ & $\$ 5$ & $\$ 6$ \\
\hline $\begin{array}{c}\text { Greater than \$4; } \\
\text { Less than or equal to \$6 }\end{array}$ & $\$ 6$ & $\$ 7$ & $\$ 8$ & $\$ 7$ & $\$ 8$ & $\$ 9$ \\
\hline $\begin{array}{c}\text { Greater than \$6; } \\
\text { Less than or equal to \$8 }\end{array}$ & $\$ 9$ & $\$ 10$ & $\$ 11$ & $\$ 10$ & $\$ 11$ & $\$ 12$ \\
\hline $\begin{array}{c}\text { Greater than \$8; } \\
\text { Less than or equal to \$10 }\end{array}$ & $\$ 12$ & $\$ 13$ & $\$ 14$ & $\$ 13$ & $\$ 14$ & $\$ 15$ \\
\hline
\end{tabular}

Before answering the next question please note that in previous runs of this experiment we found that people typically overstate their true willingness to invest by approximately $\$ 2.00$ when asked to do so in a hypothetical setting like this. Please keep this in mind when answering the next question.

\section{QUESTION \#2.}

This question requires a choice for which you would be hypothetically paid based on your answer.

Would you be willing to make an investment of $\mathbf{x x}$ dollars?

YES

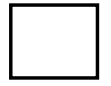

NO

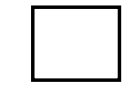




\section{Demographic Questions}

Please answer the following questions to the best of your ability. These questions are very important to us. Remember that all information is completely anonymous and confidential.

1. Gender:

Male $\square$ Female

2. Age

3. Class:

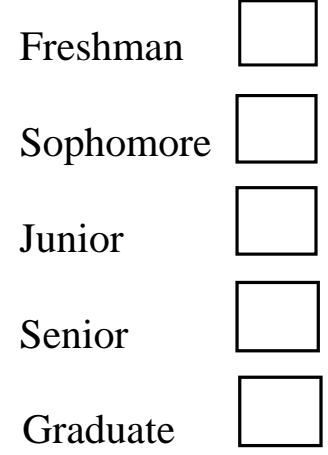

4. Cumulative GPA

5. Have you declared a major?

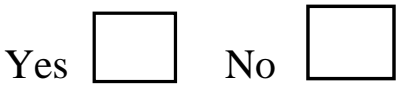

If yes, what is your major?

6. In which range do you think your before-tax annual income falls (income includes wages, salary, and money from parents but excludes student loans)?

Less than $\$ 10,000$.

Greater than $\$ 10,000$ but less than $\$ 20,000$.

Greater than $\$ 20,000$ but less than $\$ 30,000$.

Greater than \$30,000.

7. Which would you choose?

$\$ 10$ with certainty.

$50 \%$ chance of $\$ 0 ; 50 \%$ chance of $\$ 20$.

I'm indifferent between the two choices above. 
Table 1. Variable Names, Definitions and Descriptive Statistics

\begin{tabular}{cccccc}
\hline \multirow{2}{*}{ Variable } & \multirow{2}{*}{ Definition } & \multicolumn{3}{c}{ Descriptive Statistics $(\mathrm{N}=153)$} \\
\cline { 3 - 6 } & Initial WTP & Mean & SD & Min & Max \\
\hline WTP $^{0}$ & Yes to Investment $=1$; No to Investment $=0$ & 0.48 & 2.83 & 0 & 10 \\
WTP $^{1}$ & Investment Amount & 4.95 & 2.84 & 1 & 1 \\
$\tau$ & Cheap Talk $=1$; No Cheap Talk $=0$ & 0.54 & 0.50 & 0 & 9 \\
$\mathrm{C}$ & Relatively High Price $\left(\tau>\mathrm{WTP}^{0}\right)=1$; zero otherwise & 0.58 & 0.49 & 0 & 1 \\
$\mathrm{HP}$ & Relatively Low Price $\left(\tau<\mathrm{WTP}^{0}\right)=1$; zero otherwise & 0.32 & 0.47 & 0 & 1 \\
LP & & & &
\end{tabular}

\begin{tabular}{|c|c|c|c|c|}
\hline \multirow{2}{*}{ Announced Price } & \multicolumn{2}{|c|}{$\mathrm{WTP}^{0}$} & \multicolumn{2}{|c|}{$\mathrm{WTP}^{1}$} \\
\hline & Mean & $\mathrm{N}$ & Mean & $\mathrm{N}$ \\
\hline$\tau=\$ 1$ & 4.19 & 32 & 0.63 & 32 \\
\hline$\tau=\$ 3$ & 3.73 & 30 & 0.67 & 30 \\
\hline$\tau=\$ 5$ & 2.64 & 30 & 0.37 & 30 \\
\hline$\tau=\$ 7$ & 4.35 & 32 & 0.53 & 32 \\
\hline$\tau=\$ 9$ & 3.35 & 29 & 0.21 & 29 \\
\hline
\end{tabular}

Notes. SD = Standard Deviation. 
Table 2. Econometric Results

\begin{tabular}{|c|c|c|c|c|}
\hline \multirow{3}{*}{$\begin{array}{c}\text { Variables } \\
\text { (Estimated Coefficient) }\end{array}$} & \multicolumn{4}{|c|}{$\begin{array}{c}\text { WTP }^{1} \text { Dependent } \\
\text { (Interval Regression) }\end{array}$} \\
\hline & \multicolumn{2}{|c|}{$\begin{array}{c}\text { Model \#1 } \\
\text { Cheap-Talk Effect }\end{array}$} & \multicolumn{2}{|c|}{$\begin{array}{c}\text { Model \#2 } \\
\text { Partitioned CT Effect }\end{array}$} \\
\hline & Coefficient & SE & SE & Coefficient \\
\hline Initial WTP $\left(\sigma_{\varepsilon}\right)$ & $6.26^{* * *}$ & 1.30 & $7.51^{* * *}$ & 2.12 \\
\hline Investment Amount $\left(\beta_{\tau}\right)$ & $0.30 * *$ & 0.16 & $0.35^{* *}$ & 0.19 \\
\hline Cheap Talk $(\Delta)$ & -1.39 & 1.18 & & \\
\hline Relatively High Price $\times$ Cheap Talk $\left(\Delta_{\text {High }}\right)$ & & & $-3.69 * *$ & 2.28 \\
\hline Relatively Low Price $\times$ Cheap Talk $\left(\Delta_{\text {Low }}\right)$ & & & 0.36 & 2.26 \\
\hline Summary Statistics & & & & \\
\hline
\end{tabular}

Notes. $\mathrm{SE}=$ Standard Error. $\mathrm{CT}=$ Cheap Talk. ${ }^{* *}$ Significant at $5 \%$ level. $* * *$ Significant at $1 \%$ level. 
Figure 1. Stylized representation of Case 1

Panel A. Cheap Talk

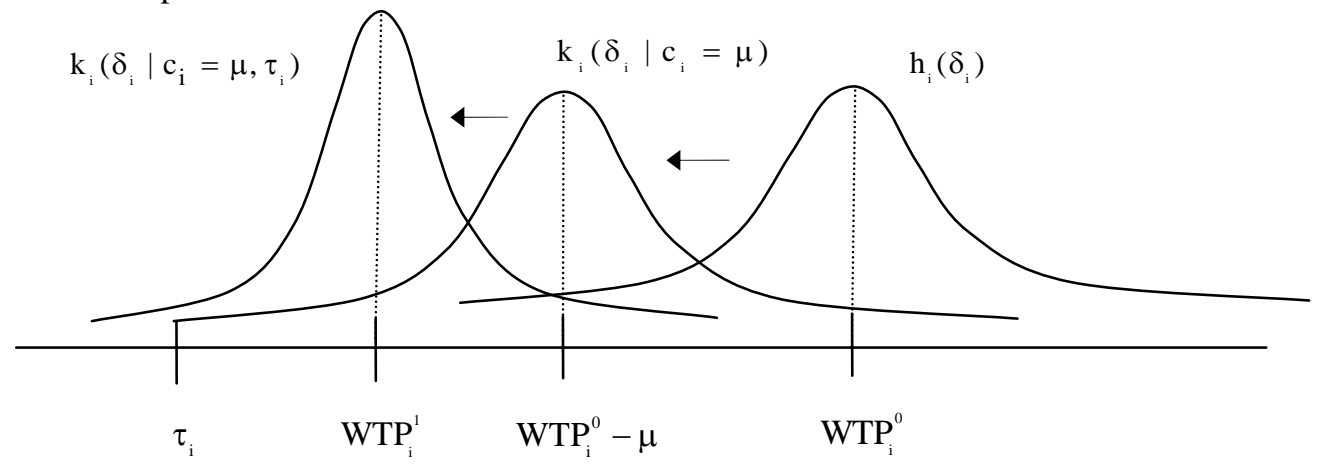

Panel B. No Cheap Talk

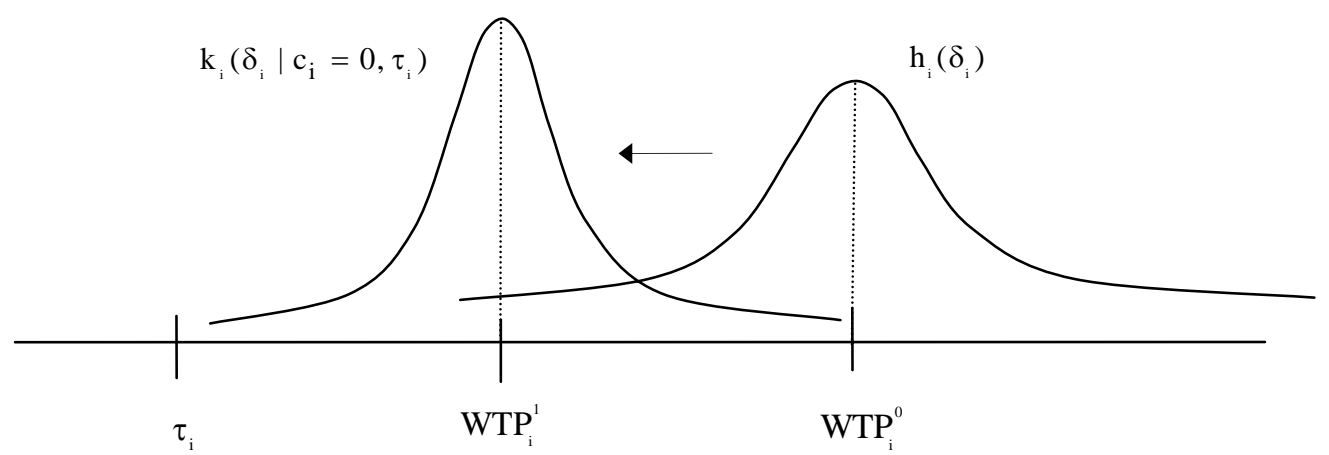


Figure 2. Relationship between $\mathrm{WTP}^{0}, \tau$ and $\Delta$

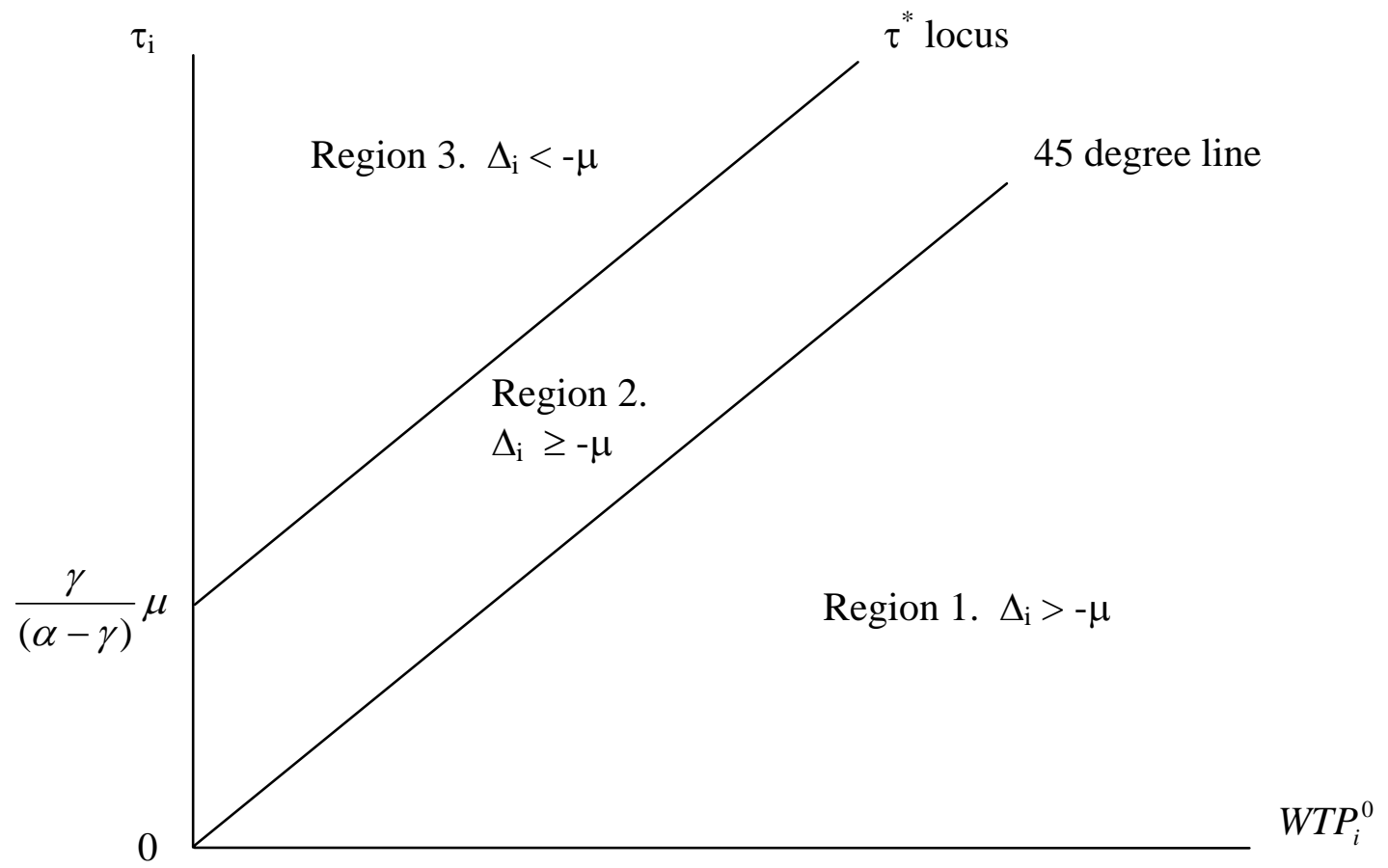

